\title{
Origem social dos parlamentares paranaenses (1995-2006): alguns achados e algumas questões de pesquisa
}

RENAIOPEISSINOIO UIZDOMINCOS COSTA* CAMIIATRIBES

\section{Resumo}

O objetivo do artigo é, seguindo algumas sugestões da literatura, traçar um perfil sócioeconômico e educacional dos parlamentares paranaenses, no período de 1995 a 2006. Pretende-se, em seguida, testar para o Paraná a hipótese de que existe alguma relação entre a posição dos partidos políticos no espectro ideológico (esquerda-direita) e a origem social dos deputados analisados. Por fim, pretendese fazer algumas sugestões de pesquisa que, caso fossem realizadas, seriam fundamentais para o avanço do estudo das elites políticas regionais e nacionais.

Palavras-chave: Elites políticas. Deputados estaduais. Paraná. O rigem social.

* Doutor em Ciências Sociais (Unicamp). Professor Adjunto do Departamento de Ciências Sociais da UFPR.

** Graduado em Ciências Sociais e pesquisador do Núcleo de Pesquisa em Sociologia Política Brasileira do Departamento de Ciências Sociais da UFPR.

*** Graduanda em Ciências Sociais e pesquisadora do Núcleo de Pesquisa em Sociologia Política Brasileira do Departamento de Ciências Sociais da UFPR. 


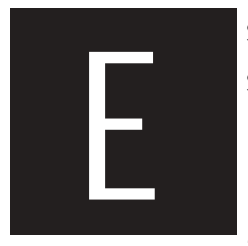

ste artigo pretende apresentar e analisar o perfil socioeconômico dos parlamentares paranaenses que ocuparam as cadeiras da Assembléia Legislativa do Estado do Paraná (ALEP) durante as 13aㅡ, 14ạ e 15a legislaturas (19952006) $)^{1}$. O nosso objetivo mais geral consiste em apresentar ao leitor os atributos pessoais, educacionais e ocupacionais que se mostram como prováveis condicionantes não insitucionais para se ter acesso ao grupo em questão durante o período analisado.

Para tanto, o presente texto divide-se em duas partes. Inicialmente, analisaremos os atributos que caracterizam a elite estudada. Esta primeira parte subdivide-se em dois itens: no primeiro deles, abordaremos aquilo que Suzanne Keller (1971, p. 160) chamou de "atributos adstritos" dos membros das elites, isto é, aqueles atributos que se referem às "características que diferenciam os indivíduos e que são tão poderosas que permanecem continuamente vinculadas a eles", tais como o gênero, a etnia, a idade e, no nosso caso, a religião; no item seguinte, discutiremos os "atributos aperfeiçoados (ou adquiridos)" (KELLER, 1971, p. 160), vale dizer, aqueles que podem ser conquistados ou valorizados ao longo da vida, tais como o nível de escolaridade e a situação social. Neste último caso, faremos ainda uma comparação entre a situação dos entrevistados e a situação de seus pais com vistas a averiguar a existência de uma mobilidade

10 artigo apresenta o resultado parcial da pesquisa "Quem governa? Mapeando as elites políticas paranaenses (1995-2006)", realizada pelo Núcleo de Pesquisa em Sociologia Política Brasileira do Departamento de Ciências Sociais da UFPR. A pesquisa aplicou um survey sobre origem social, carreira e valores políticos a três setores da elite política regional: os parlamentares, os dirigentes do Estado e os líderes partidários. 0 nosso universo inicial era composto de 251 pessoas (105 dirigentes do Estado, 111 parlamentares e 35 líderes partidários), das quais 163 foram entrevistadas, obtendo-se, assim, uma taxa de retorno geral de $65 \%$. No que diz respeito exclusivamente aos parlamentares, conseguimos aplicar o questionário a 70 indivíduos, obtendo uma taxa de retorno de $63 \%$. As considerações feitas neste texto, salvo exceções, referem-se exclusivamente aos 70 parlamentares entrevistados. A pesquisa contou com o apoio financeiro da Fundação Araucária e do CN Pq. O s autores agradecem aos pareceristas anônimos de Sociologias pelos comentários ao texto. 
social ascendente ou descendente dos membros da elite parlamentar paranaense em relação aos seus familiares. Por fim, na segunda parte deste artigo, veremos em que medida os indivíduos portadores desses atributos estão ou não distribuídos de forma padronizada entre os diferentes partid os políticos, testando para o Paraná a hipótese aventada por Rodrigues (2002) acerca da base social dos partidos políticos no Brasil. Antes, porém, de entrarmos na apresentação e análise dos nossos dados, convém fazer ainda algumas considerações quanto aos objetivos deste texto.

É preciso deixar claro antes de tudo que este artigo não constitui propriamente um estudo de "recrutamento político". Estudos de "recrutamento político", por definição, precisam analisar todas as etapas que configuram o processo seletivo de uma elite política. Nesse sentido, não é suficiente apresentar um perfil dos que "chegaram lá" e, a partir de suas características, produzir inferências sobre quais grupos sociais são prejudiciados ou privilegiados no longo caminho até as posições de elite. Por exemplo, ao traçar um perfil de elite podemos constatar a baixa presença de mulheres no grupo. No entanto, isso, por si só, não nos autoriza a dizer que as mulheres foram excluídas do grupo, pois elas simplesmente podem não se candidatar a essas posições. ${ }^{2}$ Por essa razão, um verdadeiro estudo de recrutamento deve dar conta não apenas das características socioeconômicas dos eleitos, mas também das características socioeconômicas dos membros dos partidos políticos, dos que buscam ser candidatos e dos que efetivamente são indicados como tal, comparandoas sempre com as características socioeconômicas da população em geral. Somente assim é que poderemos acompanhar, passo a passo, o processo que seleciona os que, por fim, ocuparão os postos de elite e somente

20 que, evidentemente, exige explicar por que as mulheres não se candidatam aos postos políticos. Discutiremos esse ponto mais adiante. 
assim poderemos ver quais grupos sociais simplesmente não se lançam na política, quais grupos sociais buscam a carreira política, mas são dela alijados, e quais se encontram sobrerepresentados na elite política (N O RRIS, 1997, em especial cap. 9).

O leitor com alguma experiência de pesquisa nessa área pode imaginar as dificuldades quase intransponíveis para uma pesquisa dessa natureza no Brasil (e no Paraná a situação configura-se ainda pior). Até onde sabemos, dados socioeconômicos e demográficos sobre os indivíduos que participam de todo o processo de recrutamento dentro dos partidos políticos são inexistentes. 0 máximo que encontramos quanto a este ponto foram informações sobre o gênero dos candidatos, o que nos permitiu aprofundar um pouco mais as nossas considerações sobre a situação da mulher na elite política paranaense nos últimos anos.

No entanto, o fato de este estudo, pelas impossibilidades apontadas cima, limitar-se a uma análise do perfil dos parlamentares paranaenses entrevistados não diminui, a nosso ver, a sua importância, e isso por quatro razões.

Em primeiro lugar, pesquisar as origens sociais e econômicas da elite política é um primeiro passo importante para a análise completa do comportamento político dos membros desse grupo. Dados sobre origem social podem ajudar a complementar as análises estritamente institucionalistas do comportamento parlamentar, atualmente tão em voga na ciência política. Pressupõe-se, assim, que a origem e a posição sociais estruturam "disposições duráveis", sendo, portanto, o "social background" um dos elementos da análise da profissão política (OFFERLÉ, 1999, p. 19).

Certamente, a relação entre origem socioeconômica e comportamento político está longe de ser direta e necessária. Czudnowski (1982, p. 4) observa que, de fato, nenhuma afirmação a priori sobre a relação entre origem social e comportamento político pode ser autorizada. No entanto, diz ele, "nenhuma hipótese promissora sobre tais relações pode ser sugerida 
sem informações e análises fornecidas por esses padrões de estudo(... $)^{3 "}$. O bserve-se ainda que o comportamento a ser explicado pela origem social não precisa ser aquele que produza resultados políticos específicos, como sugere Klaus von Beyne no seu estudo sobre a Alemanha de 1871 a 1976 (1982, p. 53-55). A origem social e o processo de socialização prévios à condição do político profissional podem ser úteis para explicar o "estilo político" do indivíduo, o tipo de interação que ele estabelece com seus adversários, a forma como ele encara a competição, os tipos de políticas públicas admissíveis e inadmissíveis, a adesão aos pressupostos básicos do sistema político e a sua postura frente a momentos históricos que exigem 0 reordenamento das prioridades políticas (O FFERLÉ, 1999, p. 34; RECCHI, 1996, p. 341; CARLTON, 1996, p. 11; CZUDNOW SKI, 1982, p. 9-10). Além disso, como lembra Dogan (1999, p. 172), diferentemente das atividades profissionais, não há exigência de qualquer critério técnico para que as pessoas se dediquem à atividade política. Cabe, portanto, ao analista detectar, para cada sociedade em particular, quais mecanismos (culturais, sociais, econômicos, políticos, simbólicos) operam na seleção daqueles que farão parte da elite política e na exclusão dos demais.

De qualquer forma, um estudo dessa natureza, isto é, que propusesse um vínculo entre origem social e comportamento político deveria ser "complementado" por análises da carreira política dos membros da elite, do seu ethos de grupo, do contexto institucional em que agem e de sua conduta política observável em casos específicos (GIDDENS, 1974a, p. xii; PUTNAM, 1976, p. 110; MEISEL, 1962, p. 4; DAHL, 1970 e 1997, cap. 8; SEARING, 1989, p. 109-1104.

Em segundo lugar, como afirma Eric Carlton (1996, p. 7), não há razão para confinar o estudo das elites ao problema do poder (i.e., da

3 Vale lembrar que, para Norris (1997), os estudos recentes têm, sim, mostrado haver uma estreita relação entre origem social e conteúdo das decisões políticas.

4 Estudos sobre o recrutamento de elite política brasileira em diversos períodos podem ser encontrados nos seguintes trabalhos: Love, 1982; Levine, 1982; Wirth, 1982; Fleischer, 1976 e 1981; Carvalho, 1995; Miceli, 1991, dentre outros. 
tomada de decisões). De fato, Robert Putnam observa que o estudo sobre a origem social das elites, sobretudo se for marcado por uma abordagem diacrônica, diz menos sobre a conduta desse grupo e mais sobre as características da sociedade em que seus membros são recrutados. Assim, por exemplo, o predomínio de um grupo social dentro da elite política pode dizer algo sobre a importância desse mesmo grupo no interior da sociedade ou, por outro lado, as mudanças, ao longo do tempo, na composição social da elite em questão podem ser um indicador (um sismógrafo) de que mudanças sociais mais profundas estão ocorrendo no seio da sociedade como um todo (PUTNAM, 1976, p. 43; SEKU LIC; SPO RER, 2002).

Em terceiro lugar, o estudo dos atributos socioeconômicos da elite política pode revelar o grau de homogeneidade ou heterogeneidade social do grupo. A composição social da elite, por sua vez, permite ao analista abordar vários outros pontos importantes. Inicialmente, quando analisamos o perfil socioeconômico dos membros de uma elite podemos discutir em que medida o recrutamento desse grupo expressa a estrutura de classes da sociedade em questão, ou, para usar os termos de Giddens, em que medida vigora um "recrutamento aberto" ou um "recrutamento fechado" (STAN W O RTH; GIDDENS, 1974, p. 4). O ra, essa questão é importante, no mínimo, por duas razões: de um lado, o acesso à elite política pode expressar uma dimensão da estrutura de oportunidades existentes na sociedade, isto é, em que medida as possibilidades de acesso estão abertas fundamentalmente às classes socialmente privilegiadas ou, ao contrário, em que medida elas se abrem às classes que ocupam as posições mais baixas na estrutura social'5; por outro lado, um recrutamento muito fechado torna possível uma elite mais coesa, que atue de maneira coordenada e, portanto, tendente a se transformar numa oligarquia capaz de

5 É claro que uma maior "representatividade social" da elite não está necessariamente vinculada à existência de uma democracia política. Q uanto a este ponto, cf. , por exemplo, Welsh, 1996. 
implementar o seu domínio de maneira mais decisiva ou, no outro extremo, um recrutamento muito aberto pode gerar uma elite tão fragmentada a ponto de comprometer o exercício de sua função fundamental, qual seja, a de conduzir politicamente uma dada comunidade. Em ambos os casos haveria importantes implicações para o problema da democracia (PUTNAM, 1976, p. 131; M EISEL, 1962, p. 4; BIRNBAU M , 1984, p. 270; HIGLEY et al, 1991; NORRIS, 1997, p. 6-7).

Por fim, a realidade política regional (no caso, a do Paraná) pode ser qualificada, sem receio de cometer exageros, como "terra incógnita". Desse modo, parece-nos de fundamental importância estudos sociológicos iniciais de caráter acentuadamente descritivo, que permitam aos pesquisadoresum primeiro contato aprofundado com uma realidade política tratada, na maioria das vezes, de forma pouco sistemática. A partir de então acreditamos ser possível a produção de um conhecimento que consiga estabelecer relações causais entre as variáveis apresentadas neste texto de forma essencialmente descritiva.

O s atributos adstritos: gênero, cor, idade e religião

A predominância dos homens nas atividades políticas é um dado bastante reconhecido pelos estudiosos desde há muito tempo. Embora possamos constatar um aumento intenso da participação das mulheres nos diversos ramos de atividades profissionais, o mesmo parece não acontecer no campo político. Segundo o Censo Demográfico feito pelo Instituto Brasileiro de Geografia e Estatística para o ano de 2000, o Paraná tinha 37,8\% da população economicamente ativa formada por mulheres e $62,2 \%$, por homens. ${ }^{6}$ No entanto, entre os parlamentares paranaenses entrevistados, os homens são maioria absoluta, perfazendo $95,7 \%$, contra apenas $4,3 \%$ de mulheres, isto é, apenas quatro. Essa enorme desigualdade quanto à presen- 
ça de homens e mulheres na elite parlamentar do Paraná expressa uma tendência que vem desde o fim do Estado Novo. Entre 1947 e 2006, dos 420 deputados que passaram pela Assembléia Legislativa do Paraná, apenas $9(2,1 \%)$ eram mulheres. ${ }^{7}$

O s dados mostram que, no Estado do Paraná, a inclusão das mulheres na elite política atinge patamares bem abaixo dos que encontramos para o resto do continente e do país. Segundo H tun, as Câmaras de Deputados na América Latina e no Caribe contavam, em 2001, com 15,3\% em média de mulheres (HTU N , 2001, p. 226). De acordo com Boselli (2003), a presença de mulheres no Congresso brasileiro é de $8,7 \%$ do total de deputados e senadores e de $12,5 \%$, em média, nas assembléias legislativas estaduais. Este último número, portanto, está muito acima do percentual de $4,3 \%$ de mulheres encontrados por nós para a Assembléia Legislativa do Paraná durante o período em análise (1995-2006).

Vale observar que a política de cotas para candidaturas femininas foi implementada no Brasil, na sua forma final, em 1998, quando se aprovou que os partidos políticos deveriam reservar $30 \%$ de suas vagas para candidatas. No entanto, alguns estudos têm mostrado que a política de cotas tem produzido parcos efeitos no que diz respeito à representação feminina nas casas legislativas. Por exemplo, Araújo (2001, p. 236) observa que, entre 1994 e 1998, houve um aumento de mulheres eleitas para as assembléias legislativas estaduais de $7,8 \%$ para $9,7 \%$. No entanto, a autora avalia que mesmo este pequeno aumento é menos efeito da política de cotas e mais a expressão de uma tendência que já se vinha observando na composição dos parlamentos. Segundo H tun (2001), o baixo impacto da política de cotas no Brasil explica-se, fundamentalmente, pelos efeitos perversos do sistema eleitoral conjugados com a falta de compromisso dos partidos políticos com a implementação definitiva desta política.

7 Agradecemos ao professor Emerson U rizzi Cervi por nos ceder o banco de dados que continha tais informações. 
No entanto, se tomarmos apenas as legislaturas aqui analisadas, percebemos que, no caso do Paraná, houve alguma melhora em relação a situação da presença das mulheres na elite parlamentar regional, embora ainda muito longe de se aproximar de uma situação de igualdade de gênero.

Gráfico 1. Homens e mulheres candidatos e mulheres eleitas para a Assembléia Legislativa do Paraná (1994-2002)

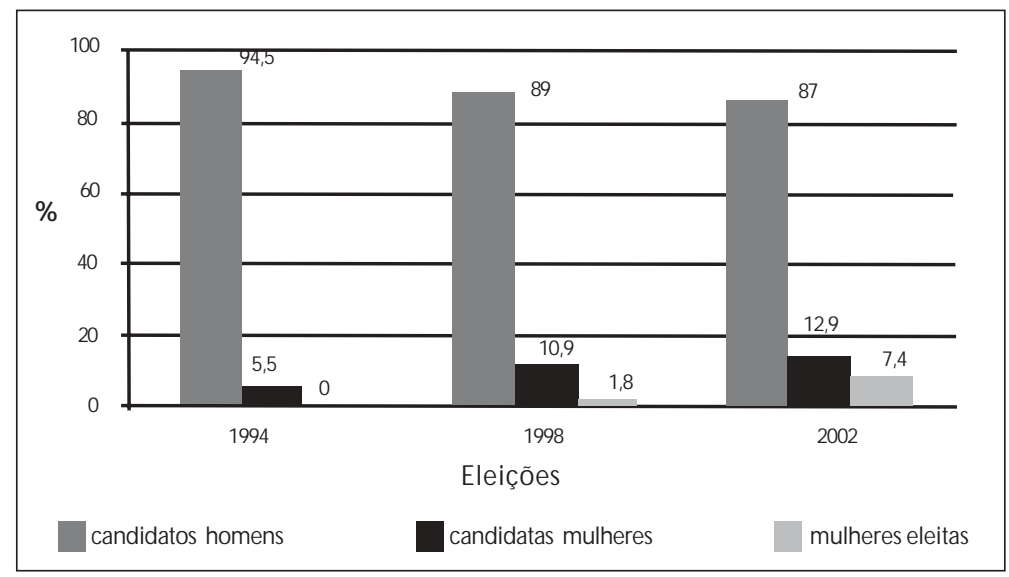

Fonte: TRE-PR.

O gráfico acima nos mostra que, em 1994, as mulheres perfaziam $5,5 \%$ do total de candidatos à ALEP, sendo que nenhuma delas foi eleita; em 1998, o número de candidatas dobrou, provavelmente em função da política de cotas, atingindo $10,9 \%$, tendo sido eleita apenas uma mulher (posteriormente outra mulher assumiu como suplente), representando 1,8\% dos componentes da Assembléia Legislativa; em 2002 a situação melhora substancialmente, com o percentual de eleitas (7,4\%) se aproximando bem mais do percentual de candidatas $(12,9 \%){ }^{8}$

80 s dados apresentados neste parágrafo referem-se ao universo total de parlamentares, e não apenas aos 70 entrevistados, e podem ser encontrados na página do Tribunal Regional Eleitoral do Paraná (http://www.tre-pr.gov.br/). 
A situação, portanto, é a seguinte: a participação das mulheres na elite parlamentar do Paraná é historicamente muito baixa. Nas últimas três legislaturas, porém, aumentou tanto o número de mulheres eleitas, como o número de mulheres que se lançaram como candidatas a uma vaga na ALEP. No entanto, mesmo que o percentual de mulheres eleitas fosse idêntico ao percentual de candidatas, caberia perguntar por que tão poucas mulheres se apresentam como postulantes ao posto de deputado estadual. ${ }^{9}$

Também é possível observar uma desproporção quanto à cor dos parlamentares. U sando os critérios do IBGE, ${ }^{10} 84,3 \%$ dos entrevistados se autodefiniram como de cor branca, 8,6\% de cor parda, 4,3\% de cor amarela e apenas 1,4\% de cor preta (um entrevistado não respondeu). Q uanto à religião indicada pelos entrevistados, a Tabela 1 mostra que a maioria é composta de católicos romanos (72,9\%), seguida de evangélicos (14,3\%), os demais distribuindo-se entre espíritas, protestantes e sem religião. ${ }^{11}$

9 Não temos a pretensão de responder essa pergunta neste artigo. Convém observar, entretanto, que os estudos recentes sobre este problema dizem que a resposta a essa questão deve ser procurada na divisão social do trabalho que caracteriza as sociedades atuais. Segundo esses estudos, as mulheres carecem de um recurso político fundamental, qual seja, tempo para dedicar-se às tarefas partidárias. Submetidas à dupla jornada de trabalho (no mercado e na vida doméstica), elas simplesmente não podem se dedicar à atividade política. Portanto, o filtro que seleciona (e exclui) as mulheres da vida política não operaria no interior das instituições políticas e nem mesmo dentro dos partidos, já que o percentual de candidatas tem se aproximado, em vários lugares, do percentual de eleitas. O u por outra: o problema da baixa presença das mulheres na elite política explica-se mais pelo lado da oferta (i.e., as dificuldades que elas têm de se apresentarem como candidatas) do que pelo lado da demanda (preconceitos sexistas da parte dos seletores intrapartidários) (NO RRIS, 1997, p. 1-14 e 228-230). De fato, embora haja incentivos institucionais explícitos (no Brasil e no resto do mundo) para que as mulheres tenham maior peso na vida política, tais incentivos têm produzido resultados sempre aquém do esperado.

10 Agregamos o grande número de cores presentes nos critérios do IBGE em branca, preta, parda, amarela e indígena.

11 As discussões sobre cor e religião são bem mais resumidas do que a relativa ao gênero dos deputados paranaenses em função, primeiro, da ausência de dados longitudinais que nos permitissem acompanhar a evolução de tais atributos ao longo do tempo e, segundo, da ausência de dados referentes ao universo dos candidatos. 
Tabela 1. Gênero, cor e religião dos deputados estaduais, da população como um todo e da PEA do Paraná

\begin{tabular}{|l|c|c|c|c|}
\hline \multirow{2}{*}{ Gênero } & & $\begin{array}{c}\text { Elite } \\
\text { Parlamentar }\end{array}$ & Paraná & PEA-Paraná \\
\cline { 2 - 5 } & & $\%(\mathrm{~N})$ & $\%$ & $\%$ \\
\hline \multirow{2}{*}{ Cor } & Masculino & $95,7 \%(67)$ & $50,47 \%$ & $62,20 \%$ \\
& Feminino & $4,3 \%(3)$ & $49,53 \%$ & $37,80 \%$ \\
& Branca & $84,3 \%(59)$ & $77,24 \%$ & $77,20 \%$ \\
& Parda & $8,6 \%(6)$ & $18,25 \%$ & $18,07 \%$ \\
& Amarela & $4,3 \%(3)$ & $0,92 \%$ & $0,94 \%$ \\
& Preta & $1,4 \%(1)$ & $2,84 \%$ & $3,13 \%$ \\
\hline Religião & Católica Romana & $72,9 \%(51)$ & $76,60 \%$ & $78,06 \%$ \\
& Evangélicas & $14,3 \%(10)$ & $16,63 \%$ & $14,98 \%$ \\
\hline
\end{tabular}

Fonte: IBGE e Núcleo de Pesquisa em Sociologia Política Brasileira - UFPR.

${ }^{1}$ O s dados para a população do Paraná como um todo e para a população ocupada acima de 10 anos de idade também foram retirados do Censo 2000, no site do IBGE. O s dados de cor e de religião da população geral e da PEA do Paraná que não ocorreram na elite parlamentar não foram incorporados à tabela. Logo, nestes casos, os percentuais não totalizam 100\%.

Os dados apresentados acima revelam que, além dos homens, outros grupos são claramente sobrerepresentados na elite parlamentar do Estado do Paraná, durante o período analisado. No que se refere à cor dos entrevistados, há, como era de se esperar, uma sobrerepresentação dos brancos. No entanto, a sobrerepresentação dos indivíduos de cor amarela é ainda mais contudente, se comparada com a presença dos mesmos na população como um todo e entre os economicamente ativos. Do lado oposto, e ao lado das mulheres, negros e pardos são claramente subrepresentados no interior da elite política regional.

A média de idade dos deputados se encontra na faixa dos 46 anos; 0 deputado mais novo tinha 22 anos quando respondeu à entrevista, e 0 mais velho tinha 66 anos. A maior parte dos parlamentares $(42,9 \%)$ se 
encontra na faixa entre 46 e 55 anos, seguidos por aqueles que se situam entre os 36 e 45 anos (31,4\%).

Os dados mostram, portanto, que o conjunto de parlamentares paranaenses entrevistados no período em análise é formado, majoritariamente, por homens brancos, católicos e situados na faixa de 36 a 55 anos. Certamente, não temos como afirmar que a posse de tais atributos adstritos seja suficiente para ter acesso è elite parlamentar do Paraná no período analisado, pois, de um lado, é evidente que nem todos os indivíduos possuidores dessas características tornam-se membros da elite política e, por outro, não temos como averiguar se os não portadores desses atributos buscaram sem sucesso uma posição no interior desse grupo. De qualquer modo, a predominância absoluta de homens brancos e a sobrerepresentação de católicos, compondo, desse ponto de vista, um grupo altamente homogêneo, ao menos nos permitem sugerir que a posse de tais atributos tornaria 0 acesso à elite parlamentar mais fácil.

\section{Os atributos adquiridos: o perfil educacional e sócio-ocupacional}

Inúmeros estudos sobre elites políticas apontam para o nível de escolaridade como um dos mais importantes requisitos para ter acesso aos postos de comando numa dada sociedade (LOVE, 1982; CARVALHO, 2003; FLEISCHER, 1976 e 1981; PINTNER, 1980; PINTNER; RO W NEY, 1980). O caso dos parlamentares paranaenses parece seguir esta regra, pois o nível de escolaridade observado entre esses indivíduos é consideravelmente elevado. De acordo com os nossos dados, 59,4\% dos entrevistados têm grau universitário completo ou acima. Além disso, 26,1\% se encontravam, no momento da pesquisa, com seus estudos superiores incompletos, dado que indica tanto aqueles que abandonaram os estudos su- 
periores como aqueles que ainda os estavam realizando no momento da entrevista. Q uanto aos restantes, 8,7\% possuem ensino médio completo e $5,7 \%$ estão situados entre os níveis médio incompleto, fundamental completo e fundamental incompleto (um entrevistado não respondeu a esta questão). Segundo os dados do IBGE, o grupo de pessoas no Paraná que, em 2000, tinha 15 anos ou mais de estudo e que, portanto, devia ter o curso superior completo, perfazia $4,5 \%$ da população. Os parlamentares paranaenses, portanto, representam uma elite não apenas do ponto de vista da posição institucional que ocupam, mas também no que se refere à posse de um dos mais importantes recursos para ter acesso ao topo das posições políticas, segundo os vários estudos citados acima. A Tabela 2 apresenta 0 perfil educacional agregado por categorias de níveis de escolaridade. ${ }^{12}$

No entanto, embora pareça figurar como um importante atributo da elite parlamentar paranaense - i. e., um atributo que de alguma forma credencia os postulantes aos postos da elite parlamentar local -, o nível educacional dos parlamentares paranaenses parece baixo se comparado aos dados referentes à elite política nacional. Por exemplo, Santos (2000) nos informa que durante a década de 1987-1999, 84,8\% dos deputados

Tabela 2. Escolaridade dos Deputados estaduais do Paraná (1995-2006) por níveis

\begin{tabular}{|l|c|c|}
\hline Níveis & Freqüência & $\%$ \\
\hline Baixa Escolaridade & 1 & 1,4 \\
Média Escolaridade & 27 & 39,1 \\
Alta Escolaridade & 41 & 59,4 \\
TOTAL & 69 & 100 \\
\hline
\end{tabular}

Fonte: Núcleo de Pesquisa em Sociologia Política Brasileira UFPR.

12 As categorias utilizadas para níveis de escolaridade foram: "alta" (curso superior ou acima); "média" (curso superior incompleto; curso médio completo ou incompleto e fundamental completo); e "baixa" (fundamental incompleto). 
federais possuíam ensino superior e Rodrigues apresenta dados muito semelhantes para os anos de 1999 e 2003 (51a legislatura da Câmara Federal), em que $82 \%$ dos deputados tinham "algum diploma superior" (RO D RIGUES, 2002 , p. 99). Tais diferenças parecem apontar para os diversos graus de exigência quanto ao nível de escolaridade entre as elites regionais e as elites nacionais. Assim entendido, o ensino superior aparece como um requisito mais decisivo ao deputado federal do que ao deputado estadual. Mais do que isso, se nos limitarmos aos atributos da elite parlamentar do Paraná, podemos afirmar que a condição de gênero (isto é, ser homem) e a condição étnica (isto é, ser branco) são bem mais decisivas para a carreira política do que o nível educacional. Portanto, no quesito escolarização, o setor parlamentar da elite política paranaense não é tão homogêneo como vimos em seus atributos adstritos e muito menos homogêneo que o setor políticoadministrativo da elite política paranaense dos anos 1995 a $2006 .^{13}$

Q uanto ao curso de formação superior, os graduados em Direito aparecem como o grupo mais expressivo: $41,5 \%$ dos que têm ensino superior foram diplomados neste curso, uma informação que denota a presen-

$13 \mathrm{Na}$ elite administrativa (composta pelos cargos do primeiro escalão da administração estadual), encontramos, num total de 72 entrevistados, 90,3\% de indivíduos situados entre os que possuem "alta escolaridade", isto é, com curso superior completo ou acima. Provavelmente, isso se explica por duas razões: a) a ocupação prévia dos membros dessa elite situa-se, majoritariamente, entre profissionais liberais e altos funcionários do setor público, compondo ambos 38,9\% do total (contra 12,9\% para a elite parlamentar). Essas duas ocupações estão intrinsecamente ligadas à obtenção de diplomas superiores, seja para o exercício mesmo da profissão (no caso dos profissionais liberais) seja para a promoção funcional dentro da burocracia de Estado (no caso do funcionalismo público); b) no caso da elite administrativa vigora o princípio autocrático de recrutamento (M O SCA, 1939, p. 394 e ss.), isto é, a indicação direta pelo chefe do Executivo. Conjugado a isso, os membros da elite administrativa são vistos como os responsáveis por gerir diretamente algumas "áreas técnicas do governo" (saúde, educação, transportes, segurança pública etc.). Desse modo, tanto o princípio de recrutamento quanto a dimensão "técnica" da atividade da elite administrativa tendem a produzir, para o período de Jaime Lerner (1995-2002) e para 0 período de Roberto Requião (2002-2006), um grupo dotado de alto nível de escolaridade. 0 recrutamento da elite parlamentar, ao contrário, depende do voto e é muito mais democrático quanto à diversidade dos que podem se apresentar como candidatos. Por essa razão, a alta escolaridade parece ser um atributo menos importante para este setor da elite política paranaense. 
ça ainda proeminente dos bacharéis em Direito nos postos políticos-chave, mas de uma forma menos acentuada que em outros períodos em que tal formação era praticamente hegemônica no interior das elites políticas do país (CARVALHO 2003, p. 84; LOVE 1982, p.393). Com o passar dos anos, essa situação se alterou substantivamente. Rodrigues $(2002$, p. 103) mostra que a Câmara Federal, durante a 51 â legislatura, contava com 31\% dos deputados federais formados no curso de Direito. Este trabalho de Rodrigues permitenos afirmar que o Paraná acompanha a tendência de diversificação dos cursos superiores próprios às lideranças políticas, mas mantendo a formação jurídica como aquela que aparece no topo da lista. As demais formações acadêmicas aparecem de forma muito fragmentada e impedem qualquer avaliação mais substantiva, com a incidência de poucos casos para cada curso.

Mesmo que os vários autores citados até o presente momento reconheçam o peso estratégico da escolaridade para o acesso às posições de elites, nenhum deles acredita que esse fato evidencia o predomínio do critério do mérito no recrutamento dos indivíduos que ocupam os postos de comando em uma dada sociedade. Segundo Putnam, ter um alto nível educacional talvez seja, na maioria dos casos, mais importante do que ter uma origem social de destaque para se inserir nas elites políticas. No entanto, este autor mostra que o nível de escolaridade sofre clara influência do status socioeconômico, isto é, o fato de um indivíduo ter um alto nível de escolaridade está intimamente ligado a sua posição privilegiada na estrutura de oportunidades da sociedade ${ }^{14}$ (PUTNAM, 1976, p. 26-32).

Por essa razão, ao se traçar o perfil de uma elite política é muito comum descrever, além do nível de escolaridade, as profissões (ou ocupações) que estas pessoas tiveram ao longo de sua vida, o que possibilita 
pensar a sua inserção no mercado de trabalho, sua posição social e, sobretudo, as profissões mais inclinadas para a atividade política. ${ }^{15}$

Com este objetivo, os parlamentares foram questionados a respeito da "profissão que exerceram por mais tempo antes de chegarem ao cargo de deputado estadual ocupado durante o período em análise". A Tabela 3 apresenta os dados desagregados em todas as categorias ocupacionais do questionário que apareceram na pesquisa: ${ }^{16}$

Como o mercado de trabalho é muito fragmentado, era de se esperar que esta questão apresentasse resultados também fragmentados, expressando uma heterogeneidade significativa no que diz respeito aos tipos de profissionais e ramos de atividades dos quais advêm os quadros do legislativo do Paraná.

Ainda assim, alguns dos dados desagregados so bre profissões são interessantes por si só. A profissão que ficou em primeiro lugar foi a de

$15 \mathrm{Na}$ verdade, acreditamos que este é o ponto mais interessante no estudo das profissões de origem dos políticos profissionais, isto é, saber quais atividades ocupacionais se constituem como pontos de partida vantajosos para o acesso à elite política. Não se trata, portando, de cometer o pecado do "sociologismo" e por simples derivação entender o comportamento do político como o resultado de sua trajetória profissional. A visão de mundo que o médico, 0 professor, o funcionário público trazem consigo acaba sempre por ser perpassada pela lógica específica do campo político (Cf. O fferlé, 1999, p. 34). De qualquer forma, parece-nos evidente não ser de menor importância que determinados grupos sociais estão "predestinados", em função dos recursos (econômicos, de tempo disponível, simbólicos) que possuem, a ter o quase monopólio da representação política. Q uanto a esse ponto, a quase ausência de trabalhadores assalariados da elite parlamentar em questão é, certamente, um dado interessante.

16 A lista de profissões apresentada ao entrevistado, incluindo as questões referentes ao seu pai e à sua mãe, foi a seguinte: pequeno proprietário rural; médio proprietário rural; grande proprietário rural; pequeno proprietário urbano (comércio, serviço e indústria); médio proprietário urbano (comércio, serviço e indústria); grande proprietário urbano (comércio, serviço e indústria); advogado atuante; profissional liberal (engenheiro, médico etc. com escritório próprio); altos cargos do setor público (diretor de empresa/banco estatal, delegado da receita estadual, desembargador, juiz etc.); funcionário público de médio ou baixo escalão; professor universitário de instituição pública ou privada; professor de outros níveis de instituição pública ou privada; comunicador (radialista, apresentador de programas de TV); jornalista (imprensa escrita ou falada); trabalhador assalariado de empresa privada (manual ou qualificado, registrado ou informal, temporário ou permanente); executivo de empresa privada; político; militar; dona de casa; não exerceu nenhuma atividade. 
Tabela 3. O cupação dos Deputados estaduais do Paraná (1995-2006)

\begin{tabular}{|l|c|c|}
\hline O cupações & Freqüência & $\%$ \\
\hline Peq. Proprietário rural & 4 & 5,7 \\
M éd. Proprietário rural & 3 & 4,3 \\
Gde. Proprietário rural & 2 & 2,9 \\
Peq. proprietário urbano & 4 & 5,7 \\
Méd. proprietário urbano & 4 & 5,7 \\
Gde. proprietário urbano & 2 & 2,9 \\
Advogado atuante & 4 & 5,7 \\
Profissional liberal & 6 & 8,6 \\
Altos cargos setor público & 3 & 4,3 \\
Funcionário público médio/baixo escalão & 10 & 14,3 \\
Professor universitário & 2 & 2,9 \\
Comunicador & 6 & 8,6 \\
Jornalista & 4 & 5,7 \\
Trabalhador assalariado empresa privada & 2 & 2,9 \\
Executivo de empresa privada & 2 & 2,9 \\
Político & 10 & 14,3 \\
Não exerceu nenhuma atividade & 1 & 1,4 \\
N R & 1 & 1,4 \\
\hline TOTAL & 70 & 100 \\
\hline
\end{tabular}

Fonte: Núcleo de Pesquisa em Sociologia Política Brasileira - UFPR

"político" (14,3\%), identificando aqueles que orientaram a sua vida profissional desde cedo e prioritariamente para a política profissional. Esses indivíduos, portanto, para usar a expressão de Max Weber, desde o início decidiram "viver da política". Na sua maioria, ocuparam o seu primeiro cargo político quando tinham por volta de 30 anos e, no momento da entrevista, quase todos tinham acima de 45 anos. A maior parte deles já tinha, também no momento da entrevista, uma carreira política de mais 
de dez anos e metade deles, acima de 20 anos. É exatamente a conjugação de uma vocação precoce para a política com uma longa carreira e com a obtenção de recursos financeiros provenientes quase que exclusivamente das atividades políticas que fazem de um indivíduo um político profissional (DOGAN, 1999, p. 171-2; O FFERLÉ, 1999, p. 14). ${ }^{17}$

Com o mesmo percentual dos políticos encontramos os funcionários públicos de médio ou baixo escalão, seguidos pelos comunicadores e profissionais liberais, ambos com 8,6\%. Em terceiro lugar encontram-se os pequenos proprietários rurais e médios proprietários urbanos, advogados e jornalistas, com $5,7 \%$, seguidos pelos médios proprietários rurais, pelos altos funcionários públicos, com 4,3\%; vindo em seguida os grandes proprietários (urbanos e rurais), professores universitários, trabalhad ores assalariados e executivos, com $2,9 \%$ cada. $^{18}$

Assim, entre as profissões mais bem colocadas - funcionalismo público, profissional liberal, comunicador, advogado e jornalista -, compondo $42,9 \%$ do total, encontramos exatamente aquelas que, para usar a expressão de Dogan (1999, p. 174), constituem-se em viveiros de políticos. Os indivíduos dedicados a esse tipo de atividade são, em geral, portadores dos requisitos básicos exigidos pela atividade política, isto é, são profissionais que têm bastante familiaridade com a escrita e a oratória. Além disso, algumas delas, em especial a atividade de funcionário público, confere ao indivíduo outras duas grandes vantagens: primeira, flexibilidade de tem-

17 Esse número de políticos profissionais pode ser ainda maior se for verdadeira também para o nosso caso a afirmação de O fferlé de que, na maioria das vezes, os "políticos profissionais", em função do estigma que acompanha a expressão, negam-se como tal e tendem a se definir como simples militantes ou pela sua profissão de origem. Q uanto a este ponto, ver o excelente texto de Damamme, 1999, em que se faz um histórico muito interessante da expressão "político profissional", desde sua estigmatização, quando surgiu em meados do século XIX, até a sua valorização recente.

18 Vale mencionar, de passagem, a incidência de apenas quatro "advogados atuantes", mostrando que número considerável de formados no curso superior de Direito não exerceu a profissão de advogado. 
po, o que é fundamental para que o indivíduo possa construir a sua candidatura dentro dos partidos políticos; segunda, a possibilidade de voltar à antiga ocupação caso fracasse na política, diminuindo assim os riscos de uma tentativa de incursão no campo político. Esses dois atributos explicam, a nosso ver, o alto número de funcionários públicos entre os parlamentares paranaenses, assim como em outros parlamentos do mundo, embora estejamos longe da funcionarização da política francesa identificada por Dogan (1999, p. 194-195).

Com a agregação das ocupações vistas acima podemos sugerir algumas conclusões sobre a posição dos parlamentares em termos de estratos sociais. A Tabela 4 hierarquiza as profissões em três estratos sociais e apresenta os seguintes resultados:

Tabela 4. Estrato social dos Deputados estaduais do Paraná (1995-2006)

\begin{tabular}{|l|c|c|}
\hline Estrato social $^{2}$ & Freqüência & $\%$ \\
\hline Estrato social baixo & 10 & 14,3 \\
Estrato social médio & 39 & 55,7 \\
Estrato social alto & 19 & 27,1 \\
Não exerceu ativid. & 1 & 1,4 \\
NR & 1 & 1,4 \\
\hline TOTAL & 70 & 100 \\
\hline
\end{tabular}

Fonte: Núcleo de Pesquisa em Sociologia Política Brasileira - UFPR

${ }^{2}$ Como não tínhamos qualquer dado objetivo para determinar a ocupação dos entrevistados, só poderíamos lançar mão da percepção subjetiva destes para determinar a sua vida profissional. A nossa lista de profissões foi elaborada seguindo três critérios: a) primeiro, ser ou não proprietário e o tamanho da propriedade; b) o lugar ocupado na divisão social do trabalho, isto é, se um trabalho manual ou intelectual e, c) por fim, de maneira bastante arbitrária, o critério da renda, que nos permitiria diferenciar os que recebem baixos salários dos que recebem alta remuneração, seja como assalariado, como profissional liberal ou como executivo. Procedimento parecido foi utilizado, por exemplo, em Werneck Vianna et. al., 1997 e em Daalder e Berg, 1982. 
Com base nos nossos dados, podemos dizer que a camada social média é a que fornece a maioria dos nomes para o legislativo estadual, composta de profissionais liberais, professores universitários, funcionários públicos, jornalistas e proprietários de médio porte, da cidade ou do campo. A presença de membros das camadas mais privilegiadas vêm em seguida, com profissões como grandes proprietários, executivos de empresas privadas, altos cargos públicos e políticos de carreira. As camadas subalternas aparecem em último lugar, representadas apenas pelos pequenos proprietários, sendo quatro deles do campo e quatro da cidade. Vale salientar que na Assembléia Legislativa do Paraná encontramos apenas dois parlamentares entrevistados que se identificaram como trabalhadores manuais assalariados.

M ais uma vez, vale insistir que a questão da participação política ou, para ser mais específico, da representatividade social da elite política é algo que não comporta apenas soluções institucionais. De um lado, temos uma ampla liberdade formal que garante 0 direito de acesso à elite política a qualquer cidadão adulto no Brasil; de outro, temos uma elite política (no Paraná e, muito provavelmente, no resto do país), marcadamente masculina, branca, católica e oriunda dos estratos médios e altos da população. Parece-nos que os filtros que operam no processo de seleção da elite política são oriundos, sobretudo, de uma "estratificação social" que distribui desigualmente recursos fundamentais para o exercício da atividade política (tempo, habilidade oral, escrita, garantias materiais etc. ). ${ }^{19}$

19 Não temos uma definição precisa de "estratificação social". Entendemos este termo como algo próximo daquilo que Michel Foucault chamou de sistema de diferenciações (1995, p. 246) ou daquilo que Giddens denominou estrutura de dominação (1994, p. 83), isto é, as posições sociais objetivas que definem a distribuição desigual de recursos sociais (simbólicos, econômicos, de autoridade, jurídicos, culturais etc.). 


\section{O s atributos socioeconômicos da família}

Examinar as variáveis socioeconômicas que podem interferir no processo de recrutamento requer um exame mais amplo desta noção de perfil social. Para tanto, um estudo dos antecedentes familiares contribui num duplo sentido: ao mesmo tempo em que qualifica os dados pessoais, educacionais e ocupacionais da elite - no sentido de perceber as relações de correspondência entre a origem familiar e a situação social encontrada possibilita observar se houve mudanças significativas entre as duas gerações, isto é, se ocorreu alguma mobilidade social (ascendente ou descendente). Desse modo podemos especular inicialmente se a situação social dos entrevistados é fruto de sua carreira política ou é uma condição prévia a ela (CAYRO L; PERRINEAU, 1982, p. 100-102).

Antes de discutir a situação social dos pais dos entrevistados, convém observar que os parlamentares revelaram não pertencer a famílias cujos pais exerciam algum tipo de atividade política regular. Com relação a este ponto, mais uma vez a situação da elite parlamentar é bem diferente da que encontramos na elite administrativa do Estado. Entre os entrevistados pertencentes a esta elite, $32 \%$ responderam que o seu pai tinha uma atividade política regular. Entre os membros da elite parlamentar, apenas 17\% deram a mesma resposta. Portanto, assim como no que se refere à escolaridade (ver nota 15), o acesso à elite parlamentar parece ser mais aberto no que diz respeito ao capital político-familiar prévio exigido do postulante ao cargo. Desse modo, parece que na elite parlamentar não encontramos, ao menos enquanto categoria predominante, o político herdeiro, isto é, aquele que recebe uma rede de relações familiares mais do que um mandato concedido pelo eleitorado (DOGAN, 1999, p. 171-172). ${ }^{20}$

No que diz respeito à situação social de suas famílias, os entrevistados responderam a respeito da "ocupação que os seus pais exerceram por

200 nosso questionário continha questões que se referiam apenas às atividades políticas do pai e da mãe. É provável que um número mais expressivo de políticos herdeiros fosse encontrado se a mesma questão fosse feita com relação aos demais parentes. 
mais tempo". A maioria dos parlamentares entrevistados (60\%) enquadrou seus pais em uma das categorias de proprietários, predominando amplamente os pequenos proprietários rurais (28,6\%), seguidos dos pequenos proprietários urbanos $(11,4 \%)$ e dos médios proprietários rurais (10\%). Há apenas três casos (4,3\%) de pais que eram grandes proprietários rurais e nenhum caso de grandes proprietários urbanos (um entrevistado não soube responder a questão). Q uanto às mães dos entrevistados, 55,7\% delas exerceram por mais tempo a ocupação de "dona de casa"; seguidas de $10 \%$ de pequenas proprietárias rurais.

Estes dados parecem apontar para traços estruturais da sociedade paranaense nas décadas de 1940 e 1950, quais sejam, de uma economia ainda essencialmente rural e muito ancorado na pequena propriedade agrícola. A elevada taxa de "donas de casa", por sua vez, demonstra que as mulheres não estavam inseridas no mercado de trabalho como hoje em dia. As duas informações parecem sugerir, na verdade, que as ocupações eram muito menos diversificadas que atualmente, pois quase metade dos pais dos entrevistados tinha as suas atividades profissionais localizadas no mundo rural e o número de mães que não se dedicavam ao cuidado do lar ou não estavam trabalhando no campo é bastante modesto $(28,6 \%$, dos quais 8,6\% eram professoras de nível secundário).

Q uand o cotejamos estas informações com aquelas referentes às ocupações dos parlamentares percebemos a diversificação (do ponto de vista profissional) substantiva que marca a passagem de uma geração para a outra. A distribuição mais ou menos equilibrada dos parlamentares em um número maior de ocupações (ou seja, a inexistência de taxas exageradamente altas para qualquer das profissões) é uma comprovação desta mudança (Tabela 3).

N ovamente, as categorias de ocupação fornecem os elementos para as categorias de estrato social e, a partir desta, cruzando os dados dos deputados com aqueles que foram fornecidos sobre os seus pais, pode- 
mos perceber algumas variações interessantes que tocam diretamente no tema da mobilidade social entre uma e outra geração, ${ }^{21}$ como se vê abaixo:

Tabela 5. Estrato social dos D eputados estaduais do Paraná em relação ao seus pais $(1995-2006)^{3}$

\begin{tabular}{|l|c|c|c|c|c|}
\hline \multirow{2}{*}{ Estrato social do pai } & \multicolumn{5}{|c|}{ Estrato social do entrevistado } \\
\cline { 2 - 6 } & $\begin{array}{c}\text { Estrato } \\
\text { social baixo }\end{array}$ & $\begin{array}{c}\text { Estrato } \\
\text { social médio }\end{array}$ & $\begin{array}{c}\text { Estrato } \\
\text { social alto }\end{array}$ & $\begin{array}{c}\text { Não } \\
\text { exerceu } \\
\text { atividade }\end{array}$ & Total \\
\hline Estrato social baixo & 9 & 20 & 9 & 0 & 38 \\
& $23,7 \%$ & $52,6 \%$ & $23,7 \%$ &, $0 \%$ & $100,0 \%$ \\
& $13,4 \%$ & $29,9 \%$ & $13,4 \%$ &, $0 \%$ & $56,7 \%$ \\
\hline Estrato social médio & 1 & 17 & 5 & 1 & 24 \\
& $4,2 \%$ & $70,8 \%$ & $20,8 \%$ & $4,2 \%$ & $100,0 \%$ \\
& $1,5 \%$ & $25,4 \%$ & $7,5 \%$ & $1,5 \%$ & $35,8 \%$ \\
\hline Estrato social alto & 0 & 2 & 3 & 0 & 5 \\
&, $0 \%$ & $40,0 \%$ & $60,0 \%$ &, $0 \%$ & $100,0 \%$ \\
&, $0 \%$ & $3,0 \%$ & $4,5 \%$ &, $0 \%$ & $7,5 \%$ \\
\hline Total & 10 & $39 \%$ & 17 & 1 & 67 \\
& $14,9 \%$ & $58,2 \%$ & $25,4 \%$ & $1,5 \%$ & $100,0 \%$ \\
\hline
\end{tabular}

Fonte: Núcleo de Pesquisa em Sociologia Política Brasileira - UFPR.

${ }^{3} \mathrm{O} N$ para as tabelas 5 e 7 é, respectivamente, 67 e 68, não tendo sido levado em consideração as não-respostas. 0 s primeiros percentuais apresentados referem-se à totalização na linha, o que permite visualizar na tabela as correlações existentes entre o estrato social do pai e o do entrevistado. O s segundos percentuais referem-se ao total dos respondentes (parlamentares), dando idéia da mobilidade social existente.

21 Como a intenção é examinar a mobilidade social entre os parlamentares e sua família de origem, utilizamos os dados sobre o pai do entrevistado, uma vez que as mães eram, na maioria, donas de casa, uma ocupação que não fornece subsídios para as classificações de estratos sociais. 
A Tabela 5 revela que 50,8\% dos deputados moveram-se para uma posição social superior à ocupada pelo pai, caracterizando-se, assim, uma mobilidade social ascendente bastante significativa. Desses 50,8\%, 29,9\% são deputados pertencentes ao estrato social médio cujos pais situavam-se no estrato social baixo; $13,4 \%$ de deputados no estrato social alto cujos pais também eram oriundos do estrato social baixo e, por fim, 7,5\% de deputados no estrato alto que tinham pais no estrato médio.

A Tabela 5 também revela a existência de um contingente de deputados que mantiveram a origem social de seus pais: $43,3 \%$ dos deputados não ascenderam, mas também não decairam socialmente; $13,4 \%$ permaneceram no estrato social baixo; $25,4 \%$ no médio e $4,6 \%$ no alto. Por fim, podemos perceber um número muito baixo de deputados (4,5\%) que percorreram uma mobilidade social descendente: dois deputados tinham pais situados no estrato social alto e se encontravam no estrato social médio; um deputado tinha 0 pai situado no estrato social médio e caiu para o estrato social baixo.

0 número de deputados que não ascenderam nem decairam socialmente em relação a seus pais (43,3\%) explica a existência de uma associação razoavelmente alta $(39 \%)$ e significativa $(\mathrm{Sig}=0,03)$ entre essas duas variáveis, mostrando que a situação social dos pais afeta a situação social dos entrevistados. ${ }^{22} \mathrm{O}$ ra, isso sugere que a carreira política, por si só, não é suficiente para explicar a situação social dos entrevistados e que, portanto, deve possuir, pelo menos para aqueles entrevistados que ocupam o mesmo estrato social de seus pais, outros atrativos que não o de ser apenas uma via de ascensão social.

A comparação dos deputados em relação aos pais aponta também para uma alta taxa de mobilidade ascendente no que diz respeito à

22 U samos o teste Gamma, que é uma medida simétrica de associação entre duas variáveis ordinais. 0 mesmo teste foi utulizado para a correlação apresentada logo abaixo. 
escolarização dos entrevistados. A Tabela 6 apresenta os dados sobre a mobilidade escolar dos deputados em relação ao seu pai:

Tabela 6. Escolaridade dos Deputad os estaduais do Paraná (1995-2006)em relação ao seus pais

\begin{tabular}{|l|c|c|c|c|}
\hline \multicolumn{5}{|c|}{ Escolaridade do entrevistado por níveis } \\
\hline $\begin{array}{l}\text { Escolaridade do } \\
\text { pai por níveis }\end{array}$ & Baixa & M édia & Alta & Total \\
\hline Sem instrução & 0 & 2 & 3 & 5 \\
& $0 \%$ & $2,9 \%$ & $4,4 \%$ & $7,4 \%$ \\
\hline Baixa & 0 & 9 & 11 & 20 \\
& $0 \%$ & $13,2 \%$ & $16,2, \%$ & $29,4 \%$ \\
\hline Média & 1 & 13 & 19 & 33 \\
& $1,5 \%$ & $19,1 \%$ & $27,9 \%$ & $48,5 \%$ \\
\hline Alta & 0 & 3 & 7 & 10 \\
& $0 \%$ & $4,4 \%$ & $10,3 \%$ & $14,7 \%$ \\
\hline Total & 1 & 27 & 40 & 68 \\
& $1,5 \%$ & $39,7 \%$ & $58,8 \%$ & $100,0 \%$ \\
\hline
\end{tabular}

Fonte: Núcleo de Pesquisa em Sociologia Política Brasileira - UFPR

Como se percebe pelos dados acima, tiveram uma mobilidade escolar ascendente $64,6 \%$ dos deputados; $29,4 \%$ deles mantiveram o mesmo nível de escolaridade de seus pais e apenas $6,0 \%$ passaram por um processo de mobilidade escolar descendente. É interessante observar que, diferentemente do que ocorre nos cruzamentos entre o estrato social do entrevistado e o estrato social de seu pai (ver Tabela 5), não há qualquer associação significativa entre o estrato social e o nível de escolaridade do pai, por um lado, e o nível de escolaridade dos filhos, por outro.

No entanto, encontramos uma correlação significativa $(\operatorname{sig}=0,02)$ e razoavelmente alta (43\%) entre a posição social do entrevistado e o seu nível de escolaridade, confirmando as sugestões de Putnam sobre a relação entre ambos. Esses dados sugerem que o nível de escolaridade dos 
entrevistados é condicionado por dois fatores: primeiro, pela a sua posição social e, segundo, pelo aumento na oferta de ensino superior ocorrido no Brasil nasúltimas décadas (o que não deve ser confundido com "democratização" do ensino).

\section{O rigem social e partidos políticos}

Para terminar este artigo, resolvemos ver se a conclusão a que Leôncio M artins Rodrigues (2002) chegou para a Câmara dos Deputados seria também válida para a Assembléia Legislativa do Estado do Paraná durante o período analisado. Segundo esse autor, valendo-se de uma metodologia bastante diferente da nossa, ${ }^{23}$ os deputados federais da 51 a legislatura distribuiam-se entre partidos presentes na Câmara de acordo com a sua origem social. Para ser mais claro, Rodrigues defende a existência de uma correlação entre a posição do partido no espectro ideológico e a composição sócio-ocupacional das bancadas dos partidos na Câmara Federal. Desse modo, PPB e PFL possuiriam bancadas socialmente mais homogêneas, com alta presença de empresários, sendo o PMDB mais heterogêneo, o que poderia explicar a sua maior indisciplina partidária; o PSD B teria uma presença baixa de empresários e de profissionais com alta escolaridade; 0 PT contaria com muitos professores qualificados e trabalhadores assalariados (2002, p. 103-110). Segundo Rodrigues, essa relativa padronização do recrutamento social nos partidos brasileiros daria ao nosso sistema partidário uma estabilidade e uma coesão maiores do que sugere o senso comum

23 Rodrigues utilizou o diploma do deputado e a última profissão exercida por ele antes de ocupar algum cargo político, tal como declarado no Repertório Biográfico da Câmara dos Deputados, como critério para definir a ocupação do mesmo. 0 nosso questionário utilizou a autodeclaração do entrevistado acerca da profissão que ele exerceu por mais tempo. Rodrigues definiu a composição social dos partidos a partir de três critérios: patrimônio, profissão e nível de escolaridade. A nossa pesquisa valeu-se apenas dos dois últimos. 
e as migrações partidárias, tão repudiadas pela opinião política corriqueira, ocorreriam dentro de limites definidos pelas bases sociais dos partidos.

No caso da Assembléia Legislativa do Paraná, os nossos dados não revelaram nada que pudesse nos levar às mesmas conclusões. É verdade que os quatro deputados que se declararam grandes proprietários (dois rurais e dois urbanos) encontram-se em partidos de centro (dois deles) e de direita (os outros dois), mas, além disso, não há qualquer relação entre origem social e partido, seja qual for o critério utilizado para fazer os cruzamentos entre essas duas variáveis. Podemos sugerir duas razões para entender essa situação.

Primeiramente, a baixa presença de grandes proprietários e a quase ausência de trabalhadores manuais assalariados (apenas dois em setenta casos) tende a atenuar a polarização de classe e, por conseguinte, a relação entre origem social e filiação partidária. Ao mesmo tempo, o predomínio das profissões típicas de classe média (37 casos) aponta para um grupo de pessoas com um espectro mais amplo de experiências profissionais e de inserção ideológica. Rodrigues também observa que é muito pouco provável que empresários estejam presentes em partidos amplamente dominados por trabalhadores assalariados e vice-versa. No entanto, é possível encontrar profissionais qualificados e professores ao lado de empresários e trabalhadores. É o caso das bancadas do PSD B (alguns empresários e profissionais qualificados) e do PT (professores qualificados e trabalhadores assalariados), indicando uma maior amplitude ideológica dos profissionais oriundos das camadas médias (2002, p. 104). O u seja, estamos apenas sugerindo (pois falta-nos elementos comparativos) que onde predomina a classe média a correlação entre origem social e posição ideológica tende a desaparecer. É o que ocorre, por exemplo, na Inglaterra, com os partidos Conservador e Trabalhista. Ambos transformaram-se, ao longo da história, cada vez mais, em partidos de classe média, sem que a distinção ideológica entre os dois desaparecesse (GUTTSMAN, 1974, p. 36; CZUDNOW SKI, 1982, p. 5).

Em segundo lugar, essa situação sugere que a opção ideológica dos indivíduos oriundos da classe média depende mais de uma socialização 
política prévia do que de sua origem social. A reforçar essa hipótese, alguns cruzamentos indicaram que os parlamentares de esquerda, em especial os vinculados ao Partido dos Trabalhadores, revelam com maior frequência passagens por cargos diretivos em movimentos sociais, entidades de trabalhadores e instituições religiosas. No entanto, os dados fornecidos pelo nosso banco de dados não são suficientes para que possamos elaborar qualquer afirmação mais contundente a respeito.

\section{Conclusão}

Como avaliar os atributos da elite parlamentar paranaense durante os anos de 1995 a 2006? Acreditamos que, valendo-nos das palavras de Giddens (1974), o recrutamento desta elite assume um caráter, ao mesmo tempo, aberto e fechado. No que diz respeito ao gênero, à etnia e à religião, a elite parlamentar paranaense é esmagadoramente formada por homens, brancos e católicos. A sobrerepresentação de homens brancos é, sem dúvida, o que chama mais atenção, fazendo desta elite um grupo altamente homogêneo. Desse modo, a condição de gênero e a etnia seriam atributos que facilitariam o acesso à Assembléia Legislativa do Paraná durante o período analisado.

Do ponto de vista de sua origem socioeconômica, o recrutamento da elite parlamentar paranaense durante o período analisado parece ser razoavelmente heterogêneo, ainda que predominem os indivíduos oriundos dos estratos sociais médios e dotados de alto nível de escolaridade. Vimos ainda que tanto a posição social quanto o nível de escolaridade representam, na grande maioria dos casos, uma mobilidade ascendente se comparados à situação em que se encontrava o pai dos entrevistados. N ão sabemos ao certo se esta ascensão social é prévia à carreira política dos entrevistados, sendo, nesse caso, um dos seus condicionantes, ou se é o 
seu resultado, tendo, neste último caso, a trajetória política impulsionado a ascensão social. Vale observar, entretanto, que não identificamos qualquer associação entre tempo de carreira e estrato social do entrevistado.

Os dados apresentados acima permitem sugerir que há mais elementos operando no processo seletivo dos parlamentares do que o processo eleitoral strictu sensu. Ainda que os mecanismos de escolha dos parlamentares por meio de eleições sejam formalmente igualitários, podemos perceber que, no final das contas, alguns indivíduos, portadores de alguns atributos específicos (homem, branco, católico, de classe média e alto nível de escolaridade), estão sobrerepresentados se compararmos esses dados com a presença desses grupos na população paranaense em geral, 0 que, de resto, como afirma Dogan (1999, p. 171), parece ser um atributo universal das elites políticas nos regimes democráticos.

No entanto, é preciso reconhecer dois limites desse nosso estudo: de um lado, nem todos os indivíduos portadores desses atributos atingem a condição de elite política, seja porque não desejam tais posições, seja porque fracassam ao buscá-las; de outro lado, não sabemos em que medida membros de outros grupos sociais se apresentam como candidatos a postos na Assembléia Legislativa e, portanto, não podemos dizer nada sobre o mecanismo social e político que opera no processo de exclusão desses grupos no longo caminho de acesso à elite parlamentar. Para usar a expressão de Birbaum (1984, p. 217), não sabemos se há intrusos tentando entrar e sendo excluídos por uma elite ciosa de seu papel e de seus atributos diferenciadores.

A nosso ver, seria de fundamental importância pesquisas que abordassem o funcionamento do processo de seleção dos membros da elite política que opera para além dos filtros formalmente reconhecidos. Pensamos que pesquisas desse tipo devem focar em duas dimensões: a) a estrutura de oportunidades políticas que a estratificação social vigente permite, 
notadamente estudos voltados para as profissões que se constituem, regularmente, em viveiros para a política. Enfim, trata-se de saber quais são as profissões que facilitam a inserção nas lides partidárias e, por conseguinte, aumentam a possibilidade de um indivíduo apresentar-se como candidato a postos no parlamento; b) o funcionamento do processo de escolha de candidatos tal como ele se desenvolve dentro dos partidos políticos. Vários estudos têm demonstrado que os partidos são o filtro político por excelência que, ao lado dos filtros sociais, acaba definindo a estrutura de oportunidades para aqueles que pretendem se dedicar à atividade política. Por essa razão, é fundamental estudar as características de seus filiados, o funcionamento do processo interno de escolha de candidatos, as características (sociais e ideológicas) dos que controlam esse processo e, por fim, 0 perfil final dos candidatos (PEN NINGS; HAZAN, 2001; HO PKIN, 2001; WESSELS, 1997; NO RRIS; LOVEDUSKI, 1997; RECCHI, 1996).

Por fim, os dados sobre os parlamentares paranaenses entre 1995 e 2006 não corroboraram a análise feita por Rodrigues que, para o caso do Brasil, estabeleceu uma clara relação entre a origem social dos parlamentares e a orientação ideológica de alguns partidos. No caso do Paraná, os dados estão mais próximos da tese de Guttsman e de Czudnowski, segundo a qual há uma tendência de partidos ideologicamente distintos recrutarem seus quadros nas classes médias. Isso parece significar que a opção desses indivíduos por partidos mais à esquerda ou mais à direita tem mais a ver com a sua socialização política prévia (na família, nos movimentos sociais e estudantis, no trabalho, nos partidos etc.) do que com a sua origem social. 


\title{
The social origin of the deputies of the state of Paraná, Brazil (1995-2006): some findings and some issues of research
}

\begin{abstract}
This article intends to draw a socioeconomic and educational profile of the deputies of the state of Paraná, from 1995 to 2006, following suggestions found in literature. Next, the paper considers the hypothesis that there is some relationship between the ideological position of the political parties (left-right) and the social origin of the surveyed deputies, within the context of Paraná. To conclude, the article provides suggestions for research, which, if they are implemented, would further advance the study of the regional and national political elites.

Keywords: Political elites. State deputies. Paraná. Social origin.
\end{abstract}

\section{Referências}

ADORN O, Sérgio. Os aprendizes do poder: o bacharelismo liberal na política brasileira. São Paulo: Paz e Terra, 1988. 266 p.

ARAÚ JO, Clara. Potencialidades e limites da política de cotas no Brasil. Estudos Feministas, Florianópolis, v. 9, n. 1, 2001. p. 231-252,

BEYNE, Klaus von. Elite Input and Policy $O$ utput: the Case of Germany. In M. M. Czudnowski (ed.), Does Who Governs Matter? Elite Circulation in Contemporary Societies. DeKalb: Northern Illino is U niversity Press, 1982. p. 55-66.

BIRNBAU M, Pierre. Dimensions du pouvoir. Paris: Presse Universitaire de France, 1984. 261 p. cap. xi ("Sur l'étude des élites").

BOSELLI, Giane. O Desafio da Política de Cotas na Conquista da Igualdade. Linha Direta, São Paulo, n. 595, ano 13,dez. 2003. p.04-05,. Disponível em: < http:// www.cfemea.org.br/publicacoes/artigos_detalhes.asp?ID Artigo =13>. Acesso em 08 jun. 2005 e 04 abr. 2006.

CARLTON, Eric. The Few and the Many: A Typology of Elites. Vermont: Scolar Press, 1996. 225 p. p. 01-32.

CARVALHO, José Murilo de. A construção da ordem: a elite política imperial; Teatro de sombras: a política imperial. Rio de Janeiro: Civilização Brasileira, 2003. $459 \mathrm{p}$. 
CAYRO L, Roland ; PERRINEAU, Pascal. Governing Elites in a Changing Industrial Society: The Case of France". In: M. M. Czudnowsky (ed.) Does Who Governs Matter? Elite Circulation in Contemporary Societies. DeKalb: Northen Illinois University Press, 1982. p. 90-124.

CZUDNOWSKI, Moshe M. Introduction: A Statement of the Issues. In M. M. Czudnowski (ed.), Does Who Governs Matter? Elite Circulation in Contemporary Societies. DeKalb: Northern Illinois University Press, 1982. p. 03-12.

DAALDER, Hans; BERG, Joop Th. J. van. Members of the Dutch Lower: Pluralism and Democratization. In: M. M. Czudnowski (ed.), Does Who Governs Matter? Elite Circulation in Contemporary Societies. DeKalb: Northern Illinois U niversity Press, 1982. p. 55-66.

DAHL, Robert A. Poliarquia. São Paulo: Edusp, 1997. p.240.

DAHL, Robert. Uma crítica do modelo de elite dirigente. In: AMO RIN , Maria Stella. Sociologia Política II. Rio de Janeiro: Zahar Editores, 1970. p. 90-100.

DAMAMME, Dominique. Professionnel de la politique, un métier peu avouable. In: OFFERLÉ, M ichel (org.), La profession politique (XIXe-XXe siècles). Paris: Éditions Belin, 1999. 363 p. p. 37-67.

DOGAN, Mattei. Les professions propices à la carrière politique. 0 smose, filières et viviers. In: OFFERLÉ, M ichel (org.). La profession politique (XIXe-XXe siècles). Paris: Éditions Belin, 1999. 363 p. p. 171-199.

FLEISCHER, David V. O pluripartidarismo no Brasil: dimensões socioeconômicase regionais do recrutamento legislativo, 1946-1967. Revista de Ciência Política, v. 24, n. 1, jan./abr. 1981. p. 49-75.

FLEISCHER, David V. Thirty years of legislative recruitment in Brasil. Washington D.C: Center of Brazilian Studies, Johns Hopkins U niversity, ago. 1976.

FO U CAULT, M ichel. O sujeito e o poder. In: RABINOW, P; DREYFUS, H. Michel Foucault: uma trajetória filosófica (para além do estruturalismo e da hermenêutica). Rio de Janeiro: Forense Universitária, 1995. 300 p. p. 231-249.

GIDDENS, Anthony. Preface e Elites in the British class structure. In: P. Stanworth ; A. Giddens (eds.), Elites and Power in British Society. Cambridge: Cambridge University Press, 1974. 274 p. p. ix-xiii e 01-21.

GIDDENS, Anthony. Central Problems in Social Theory: Action Structure and Contrdiction in Social Analysis. Los Angeles: U niversity of California Press, 1994. $294 \mathrm{p}$.

GUTTSMAN, W. L. The British Political Elite and the Class Structure. In: Stanworth and Giddens (eds.), Elites and Power in Britsh Society. Cambridge: Cambridge University Press, 1974. 274 p. p. 22-44. 
HIGLEY, John. HOFFM ANN -LANGE, U rsula; KADUSHIN, Charles and M O O RE, Gwen. Elite integration in stable democracies: a reconsideration. European Sociological Review, v. 7, n 1, mai. 1991.

HTUN, Mala. A política de cotas na América Latina. Estudos Feministas, Florianópolis, v. 9, n. 1, 2001. p. 225-230

IBGE - INSTITUTO BRASILEIRO DE GEO GRAFIA E ESTATístICA. Censo 2000. Disponível em: < www.ibge.gov.br>. Acesso em 12 mai. 2005 e 13 mar. 2006.

KELLER, Suzanne. Mas alla de la clase dirigente. Madrid: Editorial Tecnos, 1971. $354 \mathrm{p}$.

LO VE, Joseph L. A locomotiva: São Paulo na federação brasileira 1889-1937. Rio de Janeiro: Paz e Terra, 1982. $471 \mathrm{p}$.

MEISEL, James H. The Mith of the Ruling Class: Gaetano Mosca and the Elite. Michigan: Ann Arbor Paperbacks and The University of Michigan Press, 1962. 432 p. MOSCA., Gaetano. The ruling class. Elementi di scienza politica. New York, Toronto, London: Mcgraw-Hill, 1939. 514 p.

O FFERLÉ, M ichel. Professions et profession politique. In: OFFERLÉ, Michel (org.), La profession politique (XIXe-XXe siècles). Paris: Éditions Belin, 1999. 363 p. p. 07-35.

PINTNER, Walter M. The Evolution of Civil O fficialdom: 1755-1855. In: PINTNER, W. M.; RO W NEY, D. K. (eds.), Russian Officialdom: The Bureaucratization of Russian Society from the Seventeenth to the Twentieth Century. North Carolina: The U niversity of N orth Carolina Press, 1980.

PINTNER, Walter M.; ROWNEY, Don K. Officialdom and Bureaucratization: Conclusions. In: PINTNER, W. M.; ROW NEY, D. K.(eds.), Russian Officialdom: The Bureaucratization of Russian Society from the Seventeenth to the Twentieth Century. N orth Carolina: The University of N orth Carolina Press, 1980.

PUTNAM, Robert D. The comparative study of political elites. New Jersey: Printice-Hall, 1976. 246 p.

RECCHI, Ettore. Fishing from the Same Schools: Parliamentary Recrutiment and Consociationalism in the First and Second Italian Republics. West European Politics, v. 19, n. 2, abr. 1996. p. 340-359.

RO DRIGUES, Leôncio Martins. Partidos, ideologia e composição social: um estudo das bancadas partidárias da Câmara dos Deputados. São Paulo: EDU SP, 2002. 242 p.

SANTOS, Fabiano. Deputados federais e instituições legislativas no Brasil: 194699. In: BO SCHI, R; DINIZ, E; SANTOS, F., Elites políticas e econômicas no Brasil. São Paulo: Fundação Konrad Adenauer, 2000. 120 p. p. 89-117. 
SEARIN G, Donald D. Political Involvement and Socialization in Great Britain. In: CLARKE, H. D.; CZU D N O W SKI, M. M. (eds.) Political Elites in Anglo-American Democracies: Chances in Stables Regimes. Illinois: N orthen Illinois U niversity Press, 1987. 335 p. p. 109-146.

SEKU LIC, Dusko; SPO RER, Zeljka. Political Transformation and Elite Formation in Croatia. European Sociological Review. 0 xford: O xford U niversity Press, v. 18, n. 1, 2002. p. 85-100.

STANW ORTH, P.; GIDDENS, A. (eds.). Elites and Power in British Society. Cambridge: Cambridge University Press, 1974. 274 p. p. ix-xiii e 01-21.

WELSH, H elga A. Parlamentary elites in times of political transition: the case of Eastern Germany. West European Politics, Routledge, v.19, n. 3, jul. 1996. p. 507-518.

Recebido: 11/09/07 Aceite final: 15/10/07 